\title{
Influence of Ar Pressure on the Magnetic Properties of Amorphous FeGaSiB Thin Films
}

DOI:

10.1109/TMAG.2017.2696059

\section{Document Version}

Accepted author manuscript

Link to publication record in Manchester Research Explorer

\section{Citation for published version (APA):}

Abbas, Q. A., Morley, N. A., Johansson, A., \& Thomson, T. (2017). Influence of Ar Pressure on the Magnetic Properties of Amorphous FeGaSiB Thin Films. leee Transactions on Magnetics, 53(11).

https://doi.org/10.1109/TMAG.2017.2696059

\section{Published in:}

leee Transactions on Magnetics

\section{Citing this paper}

Please note that where the full-text provided on Manchester Research Explorer is the Author Accepted Manuscript or Proof version this may differ from the final Published version. If citing, it is advised that you check and use the publisher's definitive version.

\section{General rights}

Copyright and moral rights for the publications made accessible in the Research Explorer are retained by the authors and/or other copyright owners and it is a condition of accessing publications that users recognise and abide by the legal requirements associated with these rights.

\section{Takedown policy}

If you believe that this document breaches copyright please refer to the University of Manchester's Takedown Procedures [http://man.ac.uk/04Y6Bo] or contact uml.scholarlycommunications@manchester.ac.uk providing relevant details, so we can investigate your claim.

\section{OPEN ACCESS}




\title{
Influence of Ar Pressure on the Magnetic Properties of Amorphous FeGaSiB Thin Films
}

\author{
Qayes A. Abbas ${ }^{1,2}$, Student Member, IEEE, Nicola A. Morley ${ }^{1}$, Member, IEEE, August Johansson ${ }^{3}$ and Tom \\ Thomson ${ }^{3}$, Senior Member, IEEE. \\ ${ }^{1}$ Dept of Materials Science \& Engineering, University of Sheffield, Mappin Street, UK, S1 3JD \\ ${ }^{2}$ Dept of Phys, College of Education for Pure Science, University of Anbar, Anbar, Iraq \\ ${ }^{3}$ School of Computer Science, University of Manchester, Manchester, UK
}

\begin{abstract}
Magnetostrictive amorphous FeSiB and FeGaSiB thin films, thickness 50nm have been grown by the co-sputtering-evaporation technique with a range of Ar pressure (4-8 $\mu \mathrm{bar}$ ) to control the Ga percentage within the films and study their effect on the magnetic, structural and magnetostriction properties. By $x$-ray diffraction, it was found that all the films had an amorphous structure and the only peaks present were for Si substrate. Using a magneto-optical Kerr effect (MOKE) magnetometer, it found that, for the FeSiB films, the anisotropy field $\left(H_{k}\right)$ increased slowly as the pressure increased, while for the FeGaSiB films, the saturation field $\left(H_{s}\right) \approx 4000 \mathrm{~A} / \mathrm{m}$ for all pressures. For both the film sets, the coercive field $\left(H_{c}\right)$ was less than $800 \mathrm{~A} / \mathrm{m}$. The magnetostriction constants $\left(\lambda_{s}\right)$ of the FeSiB thin films increased with increasing pressure. While for the FeGaSiB films, the magnetostriction constant decreased with increasing the sputtering gas pressure, with the maximum $\lambda_{s}=11.4 \mathrm{ppm}$, at the lowest pressure $4 \mu \mathrm{bar}$. Thus it was determined that the addition of Ga atoms reduced the intrinsic stress within the films, while maintaining the amorphous morphology.
\end{abstract}

Index Terms - Magnetostrictive, thin films, amorphous, magnetic properties, MEMS.

\section{INTRODUCTION}

AOrphous magnetostrictive materials in the form of $\mathbf{1}_{\text {thin films have become of interest for }}$ microelectromechanical systems (MEMS) such as magnetostrictive sensors $[1,2]$. The inverse magnetostrictive effect in thin films is defined as a change in magnetisation under applied stress [3, 4]. Current work has demonstrated the promise of amorphous magnetic $\mathrm{FeGaSiB}$ thin films for use in applications that involve low saturation field $(<5 \mathrm{kA} / \mathrm{m})$ and high magnetostriction constant (>20ppm). These applications include low field sensors and artificial multiferroic heterostructures, which use electric fields to control the magnetisation via the strain induced by the piezoelectric substrate $[5,6]$.

Sputtering parameters such as Ar pressure affect the magnetic, structural and magnetostriction properties of the deposited films as a result of their sensitivity to the growth parameters [7]. The sputtering pressure induces intrinsic stresses, which can be either tensile or compressive dependent on varying Ar pressure [8]. Other stresses arise from the lattice misfit between the film and the substrate and the difference between the thermal expansion coefficient of both film and substrate. Javed et al [9], studied the effect of pressure on the

Manuscript received April 1, 2015; revised May 15, 2015 and June 1, 2015; accepted July 1, 2015. Date of publication July 10, 2015; date of current version July 31, 2015. (Dates will be inserted by IEEE; "published" is the date

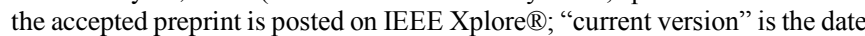
the typeset version is posted on Xplore $\left.{ }^{\circledR}\right)$. Corresponding author: N. A. morley (e-mail: n.a.morley@sheffield.ac.uk).

Color versions of one or more of the figures in this paper are available online at http://ieeexplore.ieee.org.

Digital Object Identifier (inserted by IEEE). magnetic properties and structure of magnetostrictive $\mathrm{Fe}_{100}$ ${ }_{\mathrm{x}} \mathrm{Ga}_{\mathrm{x}}(19 \leq \mathrm{x} \leq 23)$ thin films produced by co-sputteringevaporation. They found that increasing the pressure greater than $3 \mu$ bar, changed the anisotropy of the films from uniaxial to isotropic. They also found that the composition of $\mathrm{Ga}$ within the films was influenced by the pressure due to inelastic collisions with the atoms of sputtering gas, hence changed the ratio of $\mathrm{Fe}: \mathrm{Ga}$ atoms. While the effective magnetostriction constant for all the samples was a constant around $60 \mathrm{ppm}$ with varying the pressure. Further work by Javed et al [10], investigated magnetostrictive 50nm thick $\mathrm{Fe}_{100-\mathrm{x}} \mathrm{Ga}_{\mathrm{x}}(14 \leq \mathrm{x} \leq$ 32) thin films grown on Si substrates using the co-sputteringevaporation technique and studied the effect of growth parameters (Ar pressure, Power of target and Ga rate) on the structure, magnetic properties and magnetostriction constant. They found that by varying the Ar pressure and holding the other parameters constant, the $\mathrm{Fe}$ atoms were affected thermally, such that the saturation field $\left(H_{s}\right)$ decreased strongly with increasing the pressure. This was due to the intrinsic stress within the films and the change in Ga percentage. Lou et al [11] studied the addition of B to FeGa films to achieve amorphous $\mathrm{FeGaB}$ films for microwave applications. They found that $9 \%$ $\mathrm{B}$ and above gave amorphous films. For 12\% B in FeGa films the coercive field was $80 \mathrm{~A} / \mathrm{m}$, the anisotropy field was $2 \mathrm{kA} / \mathrm{m}$ and the magnetostrictive constant was $70 \mathrm{ppm}$. They didn't investigate further different Fe:Ga ratios nor the effect of sputtering pressure on the magnetic properties. While Ali [7] studied the magnetic properties of FeSiBC films as a function of Ar sputtering pressure. He found that the coercive field strongly depended on the sputter pressure.

The motivation of this work is the study of the effects of Ar pressure $\left(p_{A r}\right)$ on the growth of magnetostrictive amorphous FeSiB and FeGaSiB thin films. This paper presents an investigation of amorphous $\mathrm{FeSiB}$ and $\mathrm{FeGaSiB}$ films, comparing the result of magnetostriction constants and 
magnetic properties as a function of the Ar pressure and $\mathrm{Ga}$ addition.

\section{EXPERIMENTAL WORK}

Amorphous FeSiB and FeGaSiB thin films were deposited by a co-sputtering- evaporation system on $\mathrm{Si}$ (100) substrates which were cleaned before deposition with acetone and IPA. The amorphous films were made independent of rapid quenching processes. Si substrates were attached to a glass slide using PMMA. After deposition, the samples were cleaned again with acetone and IPA. The composition of the sputter target was $\mathrm{Fe}_{85} \mathrm{Si}_{10} \mathrm{~B}_{5}$. Two types of films were deposited with a thickness $50 \mathrm{~nm}$, sputter power $\left(\mathrm{P}_{\mathrm{FeSiB}}\right)$ of $20 \mathrm{~W}$, and the substrate-target distance $(d) 60 \mathrm{~mm}$. The first was amorphous $\mathrm{FeSiB}$ thin films for a range of Argon gas pressures ( $\left.p_{A r}\right)(4-8 \mu \mathrm{bar})$. The second was amorphous $\mathrm{FeGaSiB}$ thin films with the same pressure conditions above, but with the addition of $\mathrm{Ga}$, evaporated at a constant arbitrary rate, $R_{G a}=0.2$. The rate was measured using a rate monitor, with the evaporation power being varied to achieve a constant rate during growth. The substrate holder was rotated during the growth, to avoid the effect of the sputter gun magnetron field, which can induce anisotropy into the films. In the transverse mode, the magnetic properties of the two film sets were measured on a magneto-optical Kerr effect (MOKE) magnetometer, with the max magnetic field applied being 40 $\mathrm{kA} / \mathrm{m}$, which was sufficient to saturate the films. Characterization of the magnetic properties was carried out by measuring the normalized hysteresis loops on unstrained films. The magnetic anisotropy and saturation fields were determined by measuring the normalised hysteresis loops at different magnetic field directions with respect to an edge of the sample, with angles from $0^{\circ}$ to $180^{\circ}$. To measure the magnetostriction constant $\left(\lambda_{s}\right)$ [13] at room temperature, the inverse magnetostrictive effect (Villari effect) [10, 12] measurement was used. This was done by applying a strain to the films using different bend radii and measuring the normalised hysteresis loop for each radius. To analysis the data, the straight line method was used on the data to define the saturation field $\left(H_{s}\right)$ (or anisotropy field $\left(H_{k}\right)$ ) [14]. The $H_{s}\left(H_{k}\right)$ were plotted as a function of bending radii $(1 / R)$ and the magnetostriction constant $\left(\lambda_{s}\right)$ calculated from $[13,14]$.

$$
\lambda_{s}=\frac{d\left(H_{S}\right)}{d\left(\frac{1}{R}\right)} \frac{2 \mu \circ M_{S}\left(1-v^{2}\right)}{3 t E}
$$

Where, $E=130 \mathrm{GPa}$ is the substrate Young's Modulus, $t=380$ $\mu \mathrm{m}$ is the substrate thickness, and $v=0.28$ is the substrate poisson ration, $\mu_{0} M \mathrm{~s}$ is the films' saturation induction, and the radii were $R=300,400$ and $500 \mathrm{~mm}$.

The Bruker D2 phaser model X-ray diffractometer with the Source $\mathrm{Cu} \mathrm{K}_{\alpha 1}$ (wavelength =1.54184 $\AA$ ) was used to investigate the film's structure. In the $\theta / 2 \theta$ mode, the measurements were taken twice. The first was for the $2 \theta$ range from $30^{\circ}$ to $80^{\circ}$ to study the structure of the films (for bcc Fe $2 \theta$ $\langle 110\rangle=44.61^{\circ}$ and for bcc Fe-Ga $\left.2 \theta<110\right\rangle=44.29^{\circ}(10 \% \mathrm{Ga})$ to $43.81^{\circ}(25 \% \mathrm{Ga})[15]$ and silicon substrate (peaks at $2 \theta=69^{\circ}$
$(<004>)$ and $33^{\circ}(<200>)$. The second was for the $2 \theta$ range from $35^{\circ}$ to $55^{\circ}$ to avoid the Si substrates peaks. The DMS model 10 Vibrating sample magnetometer (VSM) was used to measure the magnetic moment of the samples at room temperature, with an external field about $40 \mathrm{kA} / \mathrm{m}$. X-ray Photoelectron Spectroscopy (XPS) using a thermo theta probe was used to determine the compositions of the films. The parameters of the measurement were dwelled time $100 \mathrm{~ms}$ (10 scans total of hi res), pass energy of $40 \mathrm{eV}$, and the source was an X-ray monochromator $\mathrm{Al} \mathrm{K}_{\alpha} \mathrm{X}$-ray. For one sample, the measurements were run three times on three different positions on the film surface and an average taken.

\section{RESULTS AND DISCUSSION}

The substrate temperature was around $19^{\circ} \mathrm{C}$ for the $\mathrm{FeSiB}$ thin film during the growth while it was around $31^{\circ} \mathrm{C}$ for FeGaSiB thin films for the variation of pressure $\left(p_{A r}\right)$. This variation in temperature should not change the growth mechanism. It is likely that the increase in temperature is due to the evaporator used during the $\mathrm{FeGaSiB}$ thin film growth, as the temperature of evaporation for the $\mathrm{Ga}$ atoms was $\sim 1000^{\circ} \mathrm{C}$, while the FeSiB was sputtered physically. Hence the addition of "hot" Ga atoms to the FeSiB films will increase the growth temperature. From the XPS measurements, for all the FeGaSiB films, Ga was detected, meaning that the Ga atoms had enough energy to travel through the plasma, without being scattered.

\section{A. XRD Results}

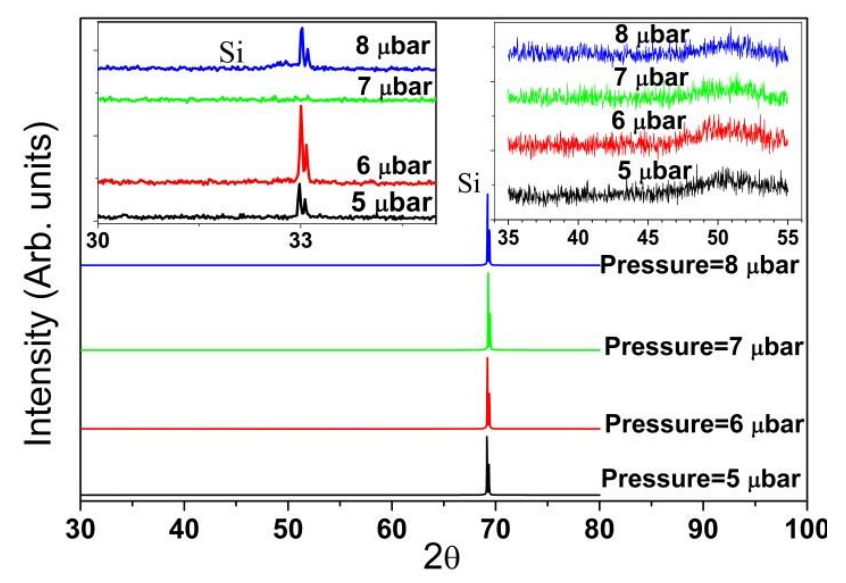

Fig. 1. XRD for the different pressures of FeGaSiB thin films. The LHS inset shows the Si peaks. The RHS shows the FeGaSiB film without the Si peaks.

Fig 1 shows the XRD of $50 \mathrm{~nm}$ thick FeGaSiB thin films for different $(\mathrm{Ar})$ gas pressures $\left(P_{A r}\right)$. The results showed that all the films had an amorphous structure and all the peaks present were for the Si substrate. The left side insert fig shows the $\mathrm{Si}$ peaks at $2 \theta 33^{\circ}$ and the right side insert fig shows the XRD pattern of the $\mathrm{FeGaSiB}$ thin films with a $2 \theta$ range $\left(35^{\circ}\right.$ to $\left.55^{\circ}\right)$ to avoid the substrate peaks. It is clear from the right side insert fig there are no peaks present at $2 \theta \sim 45^{\circ}$ to indicate the existence of crystalline $\mathrm{Fe}$ or $\mathrm{FeGa}$. There is a broad peak at $2 \theta$ $\sim 50^{\circ}$, which is expected for amorphous films. Hence all the 
films had an amorphous structure. The results show that the adding of $\mathrm{Ga}$ into amorphous $\mathrm{FeSiB}$ thin films does not affect the morphology also changing the Ar gas pressure does not affect the film morphology. This means the film morphology is independent of pressure.

\section{B. Magnetic Properties}

Fig 2 shows the results of the VSM measurements for $\mathrm{FeGaSiB}$ thin films which were measured at room temperature to avoid any thermal effects of high temperatures and to avoid annealing the films. From fig 2, it can be seen that the magnetisation of the FeGaSiB films decreases with increasing pressure. This will be due to the Ar pressure changing the percentage of non-magnetic atoms $(\mathrm{Ga}, \mathrm{Si}, \mathrm{B})$ within the films, so leading to a change in the composition of films $[9,10]$. This will be due to the increase in pressure changing the mean free paths of all the atoms, as $\mathrm{Ga}$ is evaporated it is likely to have a higher energy than the sputtered elements, meaning that its mean free paths at higher pressures is longer than the other elements, so increasing the concentration in the films. This will change the local environment within the amorphous films, as the magnetic moment of $\mathrm{Fe}$ atoms depends on the nearest neighbours.

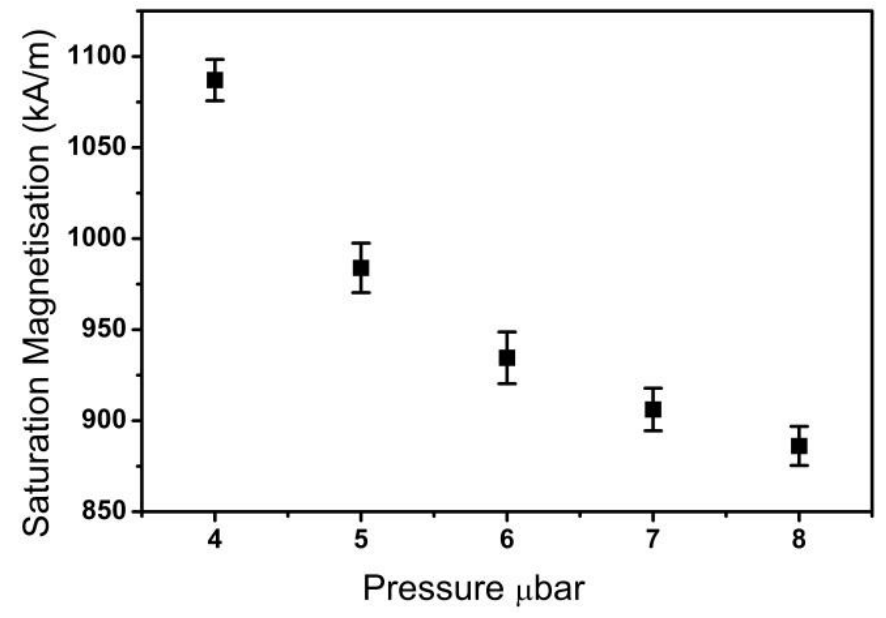

Fig. 2. Saturation magnetisation as a function of pressure for the FeGaSiB films

The anisotropy and saturation fields were determined from the unstrained hysteresis loops measured on the MOKE, as a function of the angle between the applied magnetic field and an edge of the sample. It was found that for the FeSiB films, all the films had uniaxial anisotropy, while the FeGaSiB films were isotropic. As all the films were amorphous, the anisotropy will be dominated by the stress within the films. Thus the FeSiB films have a large intrinsic stress, while the addition of $\mathrm{Ga}$ has reduced this stress within the FeGaSiB films. As the anisotropy field can be proportional to the stress in the film and is given by $[16,9]$ :

$$
H_{k} \approx \frac{2 K}{\mu_{o M_{S}}} \approx \frac{3 \lambda_{S} \sigma}{\mu_{o} M_{S}}
$$

Where $K$ is the anisotropy constant, $\mu_{\mathrm{o}} M \mathrm{~s}$ is the saturation induction and $\sigma$ is the intrinsic stress.

Fig 3 shows the effect of Ar pressure on the anisotropy/saturation fields for $\mathrm{FeSiB}$ and $\mathrm{FeGaSiB}$ films. For the $\mathrm{FeSiB}$ films, $H_{k}$ increased gradually as the pressure increased, suggesting that the intrinsic stresses within the films increased with pressure. While for the FeGaSiB films $H_{s} \approx 4000$ $\mathrm{A} / \mathrm{m}$ for all pressures. This means the addition of $\mathrm{Ga}$ into $\mathrm{FeSiB}$ reduced the stress in the films, so giving stability to the saturation field over the pressure range. Fig 4 shows the coercive fields as a function of $\mathrm{Ar}$ pressure for $\mathrm{FeSiB}$ and $\mathrm{FeGaSiB}$ thin films. For both the film sets, $H_{c}$ is less than 800 $\mathrm{A} / \mathrm{m}$, showing that neither pressure nor Ga changed the coercivity. This is expected as the coercive field strongly depends on intrinsic properties such as the grain size, and as both film sets were amorphous, the films will contain no grains.

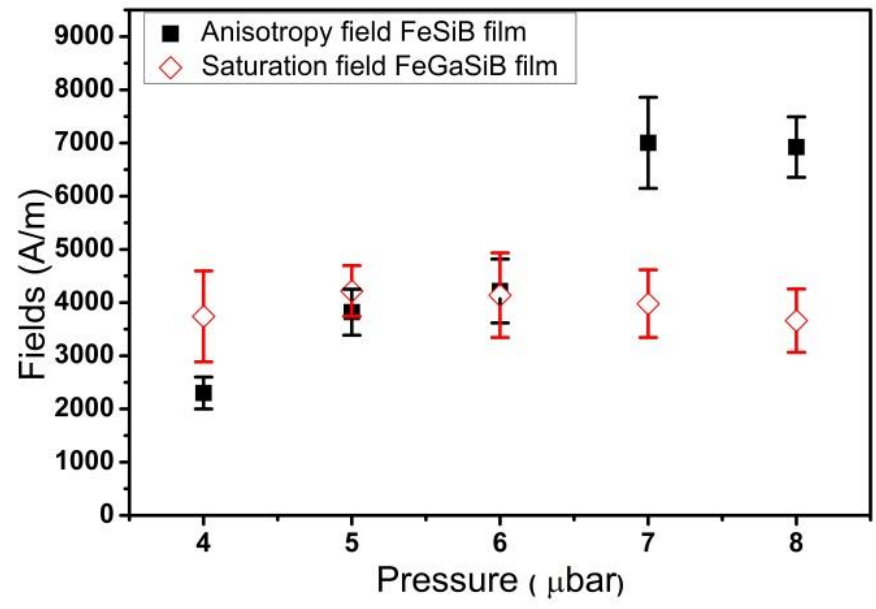

Fig. 3. Saturation/Anisotropy Fields as a function of pressure for the FeSiB and $\mathrm{FeGaSiB}$ films

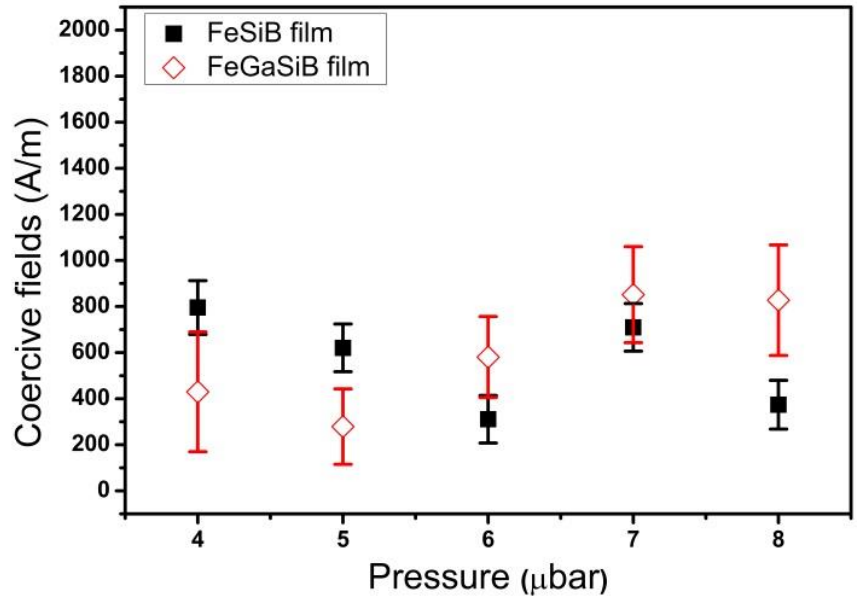

Fig. 4. Coercive Fields as a function of pressure for the FeSiB and FeGaSiB films 


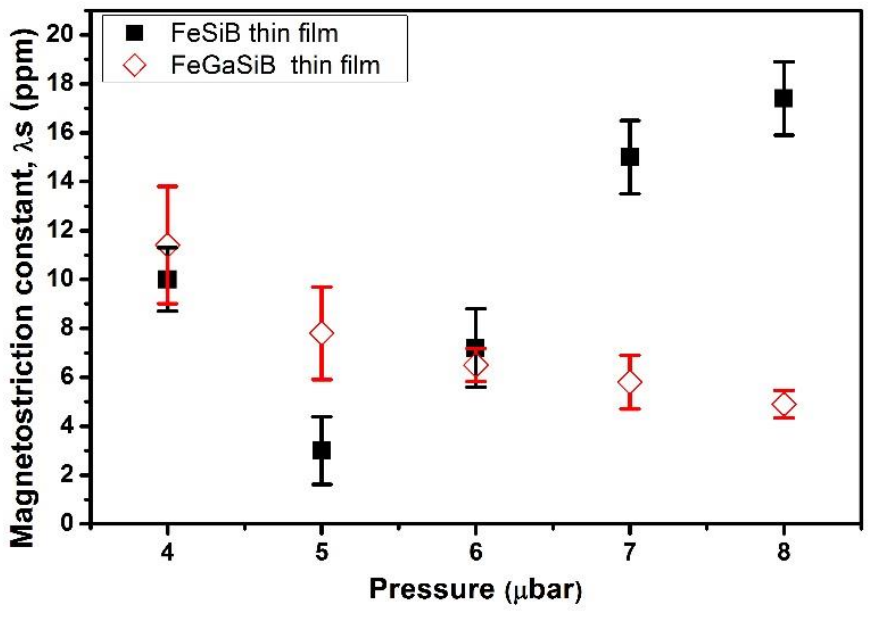

Fig. 5. Magnetostriction constant $\lambda_{s}$ as a function of pressure for the FeSiB and $\mathrm{FeGaSiB}$ films

From fig 5, it is observed that the magnetostriction constant of the $\mathrm{FeSiB}$ thin films increased with increasing pressure. From equation (2), it is observed that the magnetostriction constant, $\lambda \boldsymbol{s}$, is related to the intrinsic stress in the film. From previous work, the intrinsic stress is tensile as this leads to an increase in elastic properties, hence an increase in the magnetostriction constant, $\boldsymbol{\lambda} \boldsymbol{s}$,. Thus the increasing pressure causes an increase in tensile stress within the FeSiB films, which increased both the magnetostriction constant $\lambda \boldsymbol{s}$ and anisotropy field. While for the FeGaSiB films, the magnetostriction constant, $\boldsymbol{\lambda} \boldsymbol{s}$, decreases with an increase of sputtering gas pressure. The films have higher magnetostriction constants, $\lambda \boldsymbol{s}$, at the lower pressures compared to the FeSiB film, with the maximum $\lambda \boldsymbol{s}=11.4 \mathrm{ppm}$, at pressure $4 \mu \mathrm{bar}$. From the anisotropy and saturation field measurements, it is concluded that the addition of $\mathrm{Ga}$ reduces the tensile stress within the films, thus these intrinsic stresses no longer dominate the magnetostriction constant, $\lambda \boldsymbol{s}$,. The reduction in stress is due to the distribution of $\mathrm{Ga}$ atoms in the amorphous structure changing the local environment around the Fe atom. This means that the magnetostriction constant, $\lambda \boldsymbol{s}$, now depends on the saturation magnetization (refer to eqn (1) and (2)), which depends on the Ga concentration (Fig. 2), as both the saturation magnetisation and magnetostriction constant, $\lambda \boldsymbol{s}$, both decrease with the increase in pressure.

\section{CONCLUSIONS}

For $\mathrm{FeSiB}$ and $\mathrm{FeGaSiB}$ films changing the sputtering pressure and the addition of Ga did not affect the film morphology, as all were amorphous. For the FeSiB films, increasing the pressure increased the tensile stress within the films, which increased the saturation field and magnetostriction constant, and meant all the films had uniaxial anisotropy. Thus the large intrinsic stresses dominated the magnetic properties. The addition of $\mathrm{Ga}$ atoms to the $\mathrm{FeSiB}$ films, reduced this intrinsic stress within the films, as all the films were isotropic and had the same saturation field. The magnetisation of the
FeGaSiB films decreased as the pressure increased, suggesting an increase in $\mathrm{Ga}$ within the films. As the intrinsic stress was reduced in the $\mathrm{FeGaSiB}$ films, the magnetostriction constants were no longer dominated by the intrinsic stress, so depended on the films magnetisation. Hence, they decreased with increasing pressure.

\section{ACKNOWLEDGMENT}

The authors like to acknowledge the Iraqi Ministry of Higher Education \& Scientific Research (MOHESR) for the financial support of this work and we like to acknowledge Dr. Tom J Hayward for his help. The UK's National EPSRC XPS Users' Service (NEXUS), Newcastle University for their help to measure the composition of films. School of Computer Science, University of Manchester, for their help with VSM measurements.

\section{REFERENCES}

[1] M. R. J. Gibbs, R. Watts, W.J. Karl, A.L. Powell, R.B. Yates, "Microstructures containing piezomagnetic elements", Sensors Actuators A, Physical, vol. 59, no. (1-3), pp 229-235,1997.

[2] M. R. J. Gibbs, E. W. Hill and P. J. Wright, "Magnetic Materials for MEMS Applications”, J. Phys. D: Appl. Phys. vol. 37. P.R237-R244, 2004.

[3] E. du Tre'molet de Lacheisserie, "Magnetostriction: Theory and Applications of Magnetoelasticity", Boca Raton, CRC Press, 1993.

[4] D. Sander, "The correlation between mechanical stress and magnetic anisotropy in ultrathin films", Rep. Prog. Phys, vol. 62, p.809-858, 1999.

[5] J. Lou, M. Lou, D. Reed, Y. Ren and N. X. Sun, "Giant electric field tuning of magnetism in novel multiferroic FeGaB/Lead Zinc NiobateLead Titanate (PZN-PT) heterostructures" Adv. Mat. Vol 21, no. 46, pp. 4711-4715, 2009

[6] W-G. Yang, N. A. Morley, J. Sharp, Y. Tian and W. M. Rainforth, "Strain-mediated converse magnetoelastic coupling strength manipulation by a thin titanium layer", App. Phys. Lett, vol. 108, no. 1, pp 12901, 2016

[7] Mannan Ali, "Growth and Study of Magnetostrictive FeSiBC Thin Films for Device Application", PhD, dissertation, Dept. Of Physics \& Astronomy, The University of Sheffield, Sheffield, Uk, September 1999.

[8] N. A. Morley, S. L. Yeh, S. Rigdy, A. Javed, and M. R.J. Gibbs, "Development of a cosputtere-evaporation chamber for Fe-Ga Films", Journal of Vacuum Science and Technology A, vol. 26, no. 4, p. 581-586, 2008.

[9] A. Javed, N. A. Morley, M. R. J. Gibbs, "Structure, magnetic and magnetostrictive properties of as-deposited Fe-Ga Thin Films". J Magn Magn Mater, vol. 321, p. 2877-2882, 2009.

[10] A. Javed, T. Szumiata, N.A. Morley, M. R. J. Gibbs, “An investigationof the effect of structural order on magnetostriction and magnetic behaviour of Fe-Ga alloy thin films", Acta Materialia, vol. 58, p. 4003- 4011, 2010.

[11] J. Lou,R. E. Insignares, Z. Cai, K. S. Ziemer, M. Liu and N. X. Sun, "Soft magnetism, magnetostriction and microwave properties of FeGaB thin films", Appl. Phys. Left. Vol. 91, pp 182504, 2007

[12] N. A. Morley, A. Javed, M. R. J. Gibbs, "Effect of a forming field on the magnetic and structural properties of thin Fe-Ga films", Journal of Applied Physics, vol. 105, p. 07A912, 2009.

[13] A. Javed, N. A. Morley, M. R. J. Gibbs, "Thickness dependence of magnetic and structural properties in Fe 80 Ga 20 Thin Films", Journal of Applied Physics, vol. 107, p. 09A944, 2010.

[14] H.T. Savage and Charles Adler, "Effect of Magnetostriction in Amorphous Ferromagnets", Materials Science and Engineering, vol. 99, p. $13-18,1988$

[15] J. M. Borrego, J. S. Blazquez, C. F. Conde, A. Conde and S. Roth, "Structural ordering and magnetic properties of arc-melted FeGa lloys", Intermetallics, vol 15, p. 193-200, 2007

[16] R.C. O Handley, Modern Magnetic Materials Principles and Applications, Wiley Inc, New York, 1999. 